\title{
Melting behaviour of raw materials and recycled stone wool waste
}

\author{
Schultz-Falk, Vickie; Agersted, Karsten; Jensen, Peter Arendt; Solvang, Mette
}

Published in:

Journal of Non-Crystalline Solids

Link to article, DOI:

https://doi.org/10.1016/j.jnoncrysol.2018.01.035

Publication date:

2018

Document Version

Peer reviewed version

Link back to DTU Orbit

Citation (APA):

Schultz-Falk, V., Agersted, K., Jensen, P. A., \& Solvang, M. (2018). Melting behaviour of raw materials and recycled stone wool waste. Journal of Non-Crystalline Solids, 485, 34-41.

https://doi.org/10.1016/j.jnoncrysol.2018.01.035

\section{General rights}

Copyright and moral rights for the publications made accessible in the public portal are retained by the authors and/or other copyright owners and it is a condition of accessing publications that users recognise and abide by the legal requirements associated with these rights.

- Users may download and print one copy of any publication from the public portal for the purpose of private study or research.

- You may not further distribute the material or use it for any profit-making activity or commercial gain

- You may freely distribute the URL identifying the publication in the public portal

If you believe that this document breaches copyright please contact us providing details, and we will remove access to the work immediately and investigate your claim 


\title{
Melting Behaviour of Raw Materials and Recycled Stone Wool Waste
}

\author{
Vickie Schultz-Falk $^{\mathrm{a}, \mathrm{b}}$, Karsten Agersted ${ }^{\mathrm{c}}$, Peter Arendt Jensen ${ }^{\mathrm{b}}$, Mette Solvang $^{1 \mathrm{a}}$ \\ ${ }^{a}$ ROCKWOOL International A/S, Hovedgaden 584, DK-2640 Hedehusene, Denmark \\ ${ }^{b}$ The Technical University of Denmark, Department of Chemical Engineering, Building 229, DK-2800 Kgs Lyngby, Denmark \\ ${ }^{c}$ The Technical University of Denmark, Department og Energy, Building 780, DK-4000, Roskilde, Denmark
}

\begin{abstract}
Stone wool is a widely used material for building insulation, to provide thermal comfort along with fire stability and acoustic comfort for all types of buildings. Stone wool waste generated either during production or during renovation or demolition of buildings can be recycled back into the stone wool melt production. This study investigates and compares the thermal response and melting behaviour of a conventional stone wool charge and stone wool waste. The study combines differential scanning calorimetry (DSC), hot stage microscopy (HSM) and X-ray diffraction (XRD). DSC reveals that the conventional charge and stone wool waste have fundamentally different thermal responses, where the charge experiences gas release, phase transition and melting of the individual raw materials. The stone wool waste experiences glass transition, crystallization and finally melting. Both DSC and HSM measurements indicates that the wool waste initiates melting at a lower temperature than the conventional charge. Also DSC measurements show that the wool waste requires less energy for heating and melting than the conventional charge, making stone wool waste recycling desirable both for environmental and for process purposes.
\end{abstract}

Keywords: Stone wool, Melting, Waste, Recycling

\section{Introduction}

Stone wool is a widely used material for building insulation, to provide thermal comfort along with fire stability and acoustic comfort for all types of buildings. As the focus on environmentally friendly buildings has increased over the past decades, so has the production of stone wool. There will be an estimated amount of 2,450,000 tons of mineral wool, i.e. stone wool, glass wool and slag wool, produced in Europe in 2017 [1]. Recycling of stone wool back into the stone wool production process has thus become increasingly relevant. Ideally, the recycling should account for both stone wool waste generated during production and external stone wool waste i.e. waste resulting from demolition and renovation of buildings. The external stone wool waste is subject to a manual sorting on the building site and again at the factory before being re-introduced into theproduction process. The sorting ensures that no other types of waste are present. Both the internal and external stone wool waste contain organic binder. This binder along with any other organic wastes that might be present in the external stone wool waste will burn off once reintroduced into the furnace.

Stone wool is produced by spinning stone wool melt into fibers. The stone wool melt is traditionally produced on a cupola furnace in which blocks of coke and stone are combusted and melted, respectively. Recycling of stone wool waste in the cupola is done by casting the waste into briquettes using cement [2]. For the cupola, the individual raw materials and wool waste melts in large blocks.

This study focuses on raw materials used in a new cyclone based melting process. For this melting process pulverized raw materials are used, and therefore mixing of the materials during melting is important.

The introduction of stone wool waste into the cupola furnace is suggested to lower the coke consumption [3]. In the glass industry it is known that re-melting of recycled glass i.e. glass cullets, requires less energy than melting virgin raw materials [4].

The stone wool recipe is constructed according to the required chemical composition of the stone wool fibers that is optimized to ensure that the fibers are biosoluble [5], [6]. The stone wool melt investigated in this study comprises five raw materials; four virgin stone materials: anorthosite, dolomite, diabase and olivine sand, and a secondary raw material: LinzDonawitz (LD) slag; a waste product from steel production [7]. The chemical composition of the individual raw materials, the mixed charge and the wool waste is shown in Table 1 as determined by X-ray flourescence (XRF).

Diabase is a chosen as a raw material based on its overall chemistry that corresponds well with the final fibre chemistry; anorthosite is chosen because of its high aluminum content; dolomite for its high calcium and magnesium content; olivine sand for magnesium and iron; and finally LD slag for its calcium and iron content.

The crystalline content of some of the stone raw materials can be found in literature. Anorthosite is known to consist of plagioclase $\left(\left(\mathrm{NaAlSi}_{3} \mathrm{O}_{8}\right)-\left(\mathrm{CaAl}_{2} \mathrm{Si}_{2} \mathrm{O}_{8}\right)\right)$ [8], dolomite is a known mineral phase $\left(\mathrm{CaMg}\left(\mathrm{CO}_{3}\right)_{2}\right)$ [9] as is olivine $\left((\mathrm{Mg}, \mathrm{Fe})_{2} \mathrm{SiO}_{4}\right)[10]$.

The chemical composition of diabase is entered into a min- 
eral norm calculator [12] known as a CIPW [11] mineral norm calculator used in geology to predict mineral phases based on chemical composition. The identified phases are: plagioclase $\left(\left(\mathrm{NaAlSi}_{3} \mathrm{O}_{8}\right)-\left(\mathrm{CaAl}_{2} \mathrm{Si}_{2} \mathrm{O}_{8}\right)\right)$, hypersthene $\left((\mathrm{Mg}, \mathrm{Fe}) \mathrm{SiO}_{3}\right)$ and diopside $\left(\mathrm{MgCaSi}_{2} \mathrm{O}_{6}\right)$ as the most likely major crystalline phases.

LD slag is known to contain multiple crystalline phases: portlandite $\left(\mathrm{Ca}\left(\mathrm{OH}_{2}\right)\right)$, srebrodol'skite $\left(\mathrm{CA}_{2} \mathrm{Fe}_{2} \mathrm{O}_{5}\right)$, merwinite $\left(\mathrm{Ca}_{3} \mathrm{Mg}\left(\mathrm{SiO}_{4}\right)_{2}\right)$, larnite/belite $\left(\mathrm{Ca}_{2} \mathrm{SiO}_{4}\right)$, calcite $\left((\mathrm{Ca}, \mathrm{Mn}) \mathrm{CO}_{3}\right)$, lime $\left(\mathrm{CaCO}_{3}\right)$, dolomite $\left(\mathrm{CaMg}\left(\mathrm{CO}_{3}\right)_{2}\right)$ and $\mathrm{FeO}$.

A previous study aimed to model the melting behaviour and melting energy requirement of individual mineral materials used for stone wool production. However, the predictive capability of the model turned out to be limited [13].

Stone wool comprises amorphous glassy fibers, shots and glass fragments formed during the cascade spinning process. A scanning electron microscopy (SEM) analysis shows stone wool fibers to have a mean arithmetic diameter of $4.0 \mu \mathrm{m}$ with a standard deviation of $2.4 \mu \mathrm{m}$ and various lengths in the range of five to several hundred microns [14]. Another study shows that sieving allows fibers to pass through a $63 \mu \mathrm{m} \mathrm{m}$ sieve [18], indicating that it is in fact the diameter of the fibers that influences the particle size distribution presented on Figure 1.

The glass transition temperature and crystallization onset of stone wool depend on the specific chemical composition of the wool [15], this is therefore also expected to be the case for the melting temperature of the formed crystal phases, however data obtained on stone wool of slightly different chemistries will still provide useful knowledge of the expected melting temperatures.

Stone wool fibers are studied thoroughly with the focus on uncovering the mechanisms behind the high temperature stability of the fibers $[15,16,17,18,19]$. These investigations show the stone wool fibers crystallize when heated above $1120 \mathrm{~K}$, explaining why stone wool products keep their shape when exposed to high temperatures up until melting initiates at $1375-1425 \mathrm{~K}$ [16],[17]. The crystallization is driven by an oxidation of $\mathrm{Fe}^{2+}$ to $\mathrm{Fe}^{3+}$ that subsequently drives the migration of cations from the bulk to the surface [16]. The formed crystals are identified in multiple studies to be augite $[15,17]$, diopside [18, 19], nepheline [15] and grossular [15]. Another study [20] shows that samples comprising 50\% stone wool waste and varied amounts of clay, dolomite and cement dust have liquidus temperatures in the region 1500-1510 K and crystallization of the stone wool fibers taking place in the range $1100-1125 \mathrm{~K}$.

The objective of this study is to obtain an understanding of the difference in melting behaviour of a conventional stone wool charge and stone wool waste in order to understand and optimize the melt production process. The effect of adding wool waste to the conventional charge is investigated in terms of melting temperature and energy consumption.

\section{Experimental}

\subsection{Samples}

Samples were prepared of each of the five raw materials of the stone wool charge: anorthosite, dolomite, diabase, dlivine sand and LD slag for simultaneous thermal analysis (STA) and XRD investigations. For both investigations the raw materials were crushed using a Herzog HSM 100 pulverizing mill. The original grain sizes along with those of the crushed materials are seen on Figure 1.

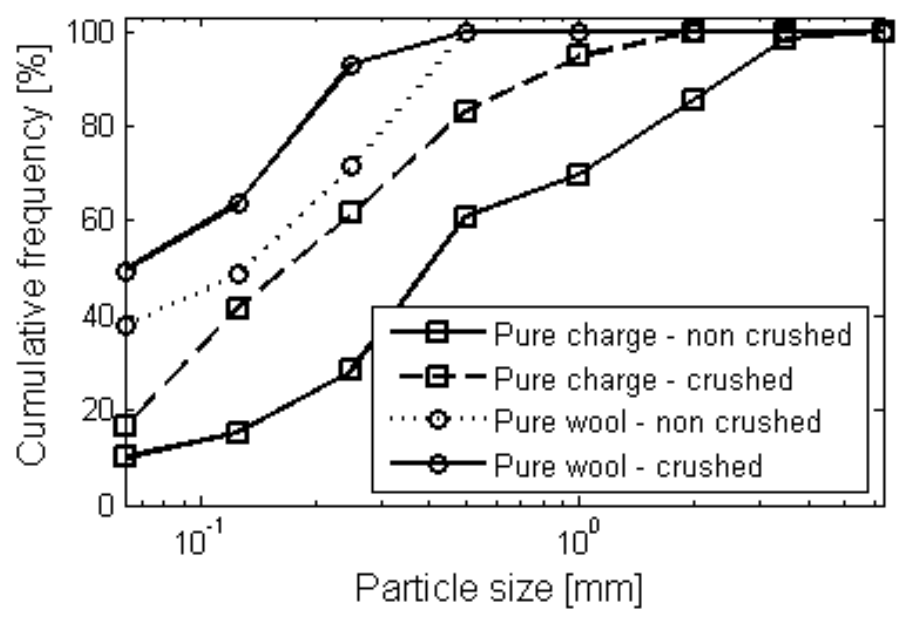

Figure 1: The particle sizes of the pure wool waste, pure charge, crushed wool waste and crushed charge measured in a sieve column with sieve dimensions of $0.063 \mathrm{~mm}, 0.125 \mathrm{~mm}, 0.25 \mathrm{~mm}, 0.5 \mathrm{~mm}, 1 \mathrm{~mm}, 2 \mathrm{~mm}, 3.5 \mathrm{~mm}$ and $6.3 \mathrm{~mm}$.

For STA and HSM investigations five samples were prepared comprising $100 \%, 75 \%, 50 \%, 25 \%$ and $0 \%$ charge and $0 \%$, $25 \%, 50 \%, 75 \%, 100 \%$ wool waste, respectively. The samples were mixed of material of original grain sizes as seen on Figure 1. The grain sizes were obtained by sieving. In order to facilitate the sieving of the fibers the organic binder in the wool waste was burned off by heating the wool waste to $863 \mathrm{~K}$ for 20 minutes prior to sieving. A rubber stamp was used to guide the fibrous material though the sieve.

For the STA measurements and selected HSM experiments the mixed samples were crushed to the sizes seen on Figure 1.

For the XRD measurements samples of pure charge and pure stone wool waste were exposed to heat treatment. $50 \mathrm{~g}$ of the material, either pure charge or pure wool waste of the original grain sizes, were placed in platinum crucibles in a hot oven at either $1473 \mathrm{~K}$ or $1623 \mathrm{~K}$ for 30 minutes. The samples were then immediately quenched in water, dried and subsequently crushed. The crushed samples were then investigated by XRD.

\subsection{STA}

A NETSZCH STA 449 F1 Jupiter simultaneous thermal analyzer was used to conduct simultaneous Differential Scan- 
ning Calorimetry (DSC) and Thermogravimetric (TG) measurements.

The individual raw materials analyzed by STA were investigated using Pt crucibles and a two-step measurement: a baseline measurement on the empty Pt crucible and a sample measurement of approximately $30 \mathrm{mg}$ of sample material. The heating rate was $20 \mathrm{~K} / \mathrm{min}$ and the maximum temperature was $1748 \mathrm{~K}$. A thin sapphire disk was placed between the crucibles and the sample holder to ensure that the platform and crucible would not fuse together during measurement.

An optimized 3-step procedure was applied to the samples comprising mixtures of charge and wool waste, respectively. A thin $\mathrm{Al}_{2} \mathrm{O}_{3}$ disk was used to separate sample holder and crucible, the thinner disk provided better thermal contact. Each measurement was carried out using previously unused $\mathrm{Pt}$ crucibles that were oxidized at $1273 \mathrm{~K}$ for 30 minutes. The empty reference crucibles were not touched in-between the 3 measurement steps: A baseline measurement on an empty crucible, a standard measurement on a sapphire standard and a sample measurement, all carried out at a heating rate of $20 \mathrm{~K} / \mathrm{min}$. The use of a standard measurement enabled the calculation of apparent heat capacity directly from the DSC measurements [21]. These measurements are carried out with a maximum temperature of $1523 \mathrm{~K}$, since measurements at higher temperatures seems to be subject to higher uncertainties.

\section{3. $H S M$}

The melting behaviour of two series comprising samples of $100 \%, 75 \%, 50 \%, 25 \%, 0 \%$ charge and $0 \%, 25 \%, 50 \%$, $75 \%, 100 \%$ wool waste, respectively, was investigated by optical dilatometry (TOMMI Frauenhofer ISC). The first series comprised samples of original grain sizes and in the second series samples that were crushed. Each sample comprised material pressed into a $6 \mathrm{~mm}$ wide cylindrical pellets with an approximate height of $6 \mathrm{~mm}$. The material was pressed in a 1.5 ton press for 20 seconds. Measurements were carried out with a heating rate of $5 \mathrm{~K} / \mathrm{min}$. Height, width and area measures were determined based on the sample outline every $1.5 \mathrm{~K}$. Images were initially acquired every $25 \mathrm{~K}$ this was then adjusted to every $5 \mathrm{~K}$ for better visualization of the melting.

\section{4. $X R D$}

XRD (Empyrean, PANalytical) measurements were carried out in the range $5^{\circ} \leq 2 \Theta \leq 70^{\circ}$ with a step size of $0.0130^{\circ}$. Six successive scans were carried out on each sample, and the data presented here is a summation over the six measurements. The anode material was copper. Based on the spectra and the chemical composition of the materials, crystal phases are identified. To identify the crystal phases in the complex spectrum of the charge, XRD spectra are first obtained of the individual raw materials, allowing for identification of the crystal phases contained in each individual raw material. These phases are then used as a subset for phase identification in the mixed charge spectrum.

\section{Results}

\subsection{STA}

Figure 2 shows the measured DSC curve for the five raw materials: anorthosite, dolomite, diabase, olivine sand and LD slag along with the mixed charge and stone wool waste. The dashed line shows a weighted sum over the individual raw materials according to the charge recipe. The descending curvature of the anorthosite, diabase and dolomite at high temperatures, i.e. above $900^{\circ} \mathrm{C}$, is attributed to an experimental error and not to any physical processes occurring in the samples. This descending curvature is naturally also reflected in the weighted sum. The weighted sum is meant to highlight the differences between the DSC measurement of the mixed charge and that of the combined individual raw materials.

Figure 3 shows the obtained TG curves of the individual raw materials. All materials are dried prior to the measurements. The total weight loss of the materials are $0.5 \%$ for olivine and diabase, $2 \%$ for anorthosite, $3 \%$ for LD slag and $48 \%$ for dolomite.

Figure 4 shows the apparent heat capacities obtained for samples comprising 100\%, 75\%, 50\%, 25\%, 0\% charge and $0 \%, 25 \%, 50 \%, 75 \%, 100 \%$ wool waste, respectively. From the apparent heat capacities the total energy consumption associated with heating and melting the samples can be calculated through integration. For the purpose of the energy calculation a total of three DSC measurements are carried out for the samples comprising $100 \%, 50 \%$ and $0 \%$ charge. The resulting energy curve is seen on Figure 5.

\section{2. $H S M$}

Based on the measured height, width and area data, the temperatures at which the sample assumes some well-known characteristic shapes are determined. The characteristic shapes are defined here: initial deformation temperature (IT), spherical temperature (ST), hemispherical temperature (HT) and flow temperature (FT). These temperatures are calculated based on definitions stated by Stabile et al [22]. HSM is carried out on two series: one of original grain sizes and one of crushed samples. For 6 out of the 10 investigated samples the images obtained are shown in Figure 6. Note that images are not acquired as often as the height and width data, and that these images thus represent the closest image to the calculated shape temperature. The temperatures at which the characteristic shapes are reached for both series are shown in Figure 7.

\section{3. $X R D$}

The XRD spectra obtained for pure charge and pure wool waste exposed to: no heat treatment, $1473 \mathrm{~K}$ for 30 minutes and $1623 \mathrm{~K}$ for 30 minutes, is seen on Figure 8.

The identified crystal phases and the corresponding raw materials are: plagioclase and quartz (anorthosite), diopside (diabase), portlandite, belite, srebrodol'skite (LD slag), dolomite (dolomite) and olivine sand (olivine). For the wool waste the identified crystal phases appearing after heat treatment at $1200^{\circ} \mathrm{C}$ for 30 minutes are: plagioclase and diopside. 


\begin{tabular}{|c|c|c|c|c|c|c|c|}
\hline & An. & Do. & Di. & Ol. & LD & Ch. & Wo. \\
\hline $\mathrm{SiO}_{2}$ & 47.6 & 0.4 & 52.1 & 41.5 & 10.6 & 42.8 & 42.6 \\
$\mathrm{Al}_{2} \mathrm{O}_{3}$ & 28.6 & 0.0 & 14.0 & 0.1 & 0.5 & 18.4 & 18.1 \\
$\mathrm{TiO}_{2}$ & 0.2 & 0.0 & 1.7 & 0.0 & 1.3 & 0.7 & 0.8 \\
$\mathrm{Fe}_{2} \mathrm{O}_{3}$ & 1.4 & 0.1 & 11.7 & 7.2 & 23.3 & 7.5 & 7.1 \\
$\mathrm{CaO}$ & 13.6 & 29.8 & 8.9 & 0.2 & 40.1 & 18.1 & 18.3 \\
$\mathrm{MgO}$ & 0.9 & 21.9 & 4.8 & 49.9 & 10.5 & 9.2 & 8.4 \\
$\mathrm{Na}_{2} \mathrm{O}$ & 2.6 & 0.0 & 2.5 & 0.0 & 0.0 & 2.0 & 2.1 \\
$\mathrm{~K}_{2} \mathrm{O}$ & 1.0 & 0.3 & 1.1 & 0.4 & 0.6 & 1.0 & 0.6 \\
$\mathrm{P}_{2} \mathrm{O}_{5}$ & 0.0 & 0.0 & 0.2 & 0.0 & 0.4 & 0.3 & 0.4 \\
$\mathrm{MnO}$ & 0.0 & 0.0 & 0.2 & 0.1 & 3.0 & 0.2 & 0.3 \\
$\mathrm{LOI}$ & 2.3 & 46.4 & 1.2 & 0.4 & 1.4 & - & 2.1 \\
\hline sum & 98.1 & 98.9 & 98.3 & 99.8 & 91.6 & 100.2 & 100.8 \\
\hline
\end{tabular}

Table 1: Chemical composition of the investigated raw materials, charge and wool waste as determined by XRF given in wt\%. An.: Anorthosite, Do.: Dolomite, Di.: Diabase, Ol.: Olivine sand, LD: LD slag, Ch.: charge, Wo.: stone wool waste.

\begin{tabular}{|l|l|l|l|l|l|l|}
\hline & \multicolumn{3}{|c|}{ Charge } & \multicolumn{3}{c|}{ Wool waste } \\
\hline & a) & b) & c) & d) & e) & f) \\
\hline Plagioclase & x & x & x & & x & \\
Dolomite & x & & & & & \\
Diopside & x & x & & & x & \\
Olivine & x & x & & & & \\
Srebrodol'skite & $\mathrm{x}$ & & & & & \\
Belite & $\mathrm{x}$ & & & & & \\
\hline
\end{tabular}

Table 2: Crystal phases identified based on the XRD data presented on Figure 8. Columns $(\mathrm{a}, \mathrm{d}),(\mathrm{b}, \mathrm{e})$ and $(\mathrm{c}, \mathrm{f})$ represent samples that are non-heated, heated to $1473 \mathrm{~K}$ for $30 \mathrm{~min}$ and heated to $1623 \mathrm{~K}$ for $30 \mathrm{~min}$, respectively.

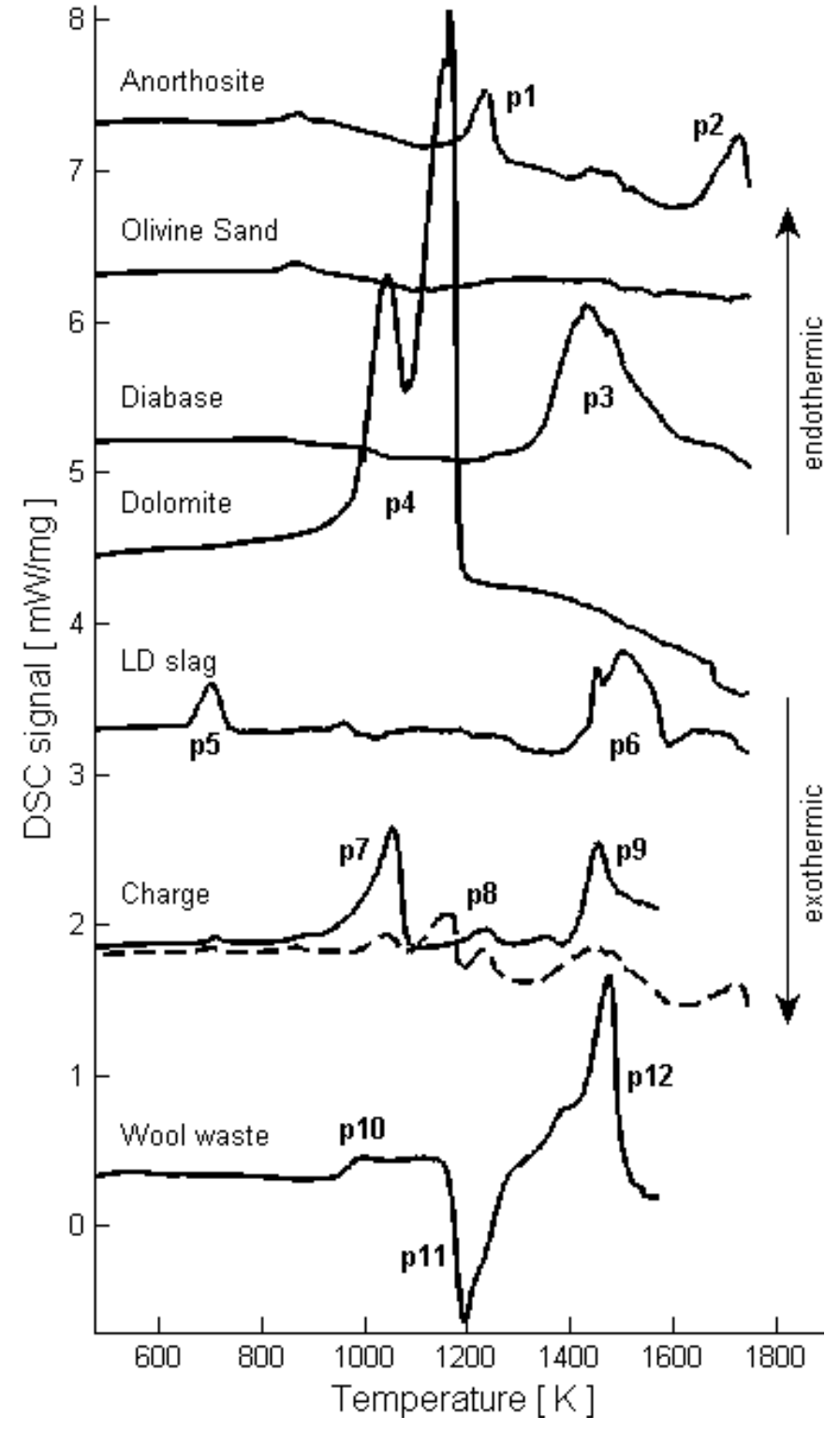

Figure 2: DSC measurements of the five individual raw materials along with the mixed charge and stone wool waste. The dashed curve indicates a weighted sum over the DSC signals of the individual raw materials according to the charge recipe. The individual curves are shifted upwards by $7 \mathrm{~mW} / \mathrm{mg}$ (anorthosite), 6 $\mathrm{mW} / \mathrm{mg}$ (olivine sand), $5 \mathrm{~mW} / \mathrm{mg}$ (diabase), $4 \mathrm{~mW} / \mathrm{mg}$ (dolomite), $3 \mathrm{~mW} / \mathrm{mg}$ (LD slag) and $1.5 \mathrm{~mW} / \mathrm{mg}$ (Charge). The wool waste curve is not shifted. Measurements were carried out at a heating rate of $20 \mathrm{~K} / \mathrm{min}$ in Pt crucibles in an Ar atmosphere. $\mathbf{p} 1$ results from an albite phasetransition, $\mathbf{p} 2$ from melting, $\mathbf{p} 3$ from melting, $\mathbf{p} \mathbf{4}$ from decarbonization, $\mathbf{p} 5$ from $\mathrm{CO} 2$ release, textbfp6 from melting, $\mathbf{p 7}$ from decarbonization of dolomite, $\mathbf{p 8}$ from the albite phase transition, $\mathbf{p} \mathbf{9}$ from melting of the mixed charge, $\mathbf{p 1 0}$ from a glass transition in the wool waste, p11 from crystallization and $\mathbf{p 1 2}$ from melting. 

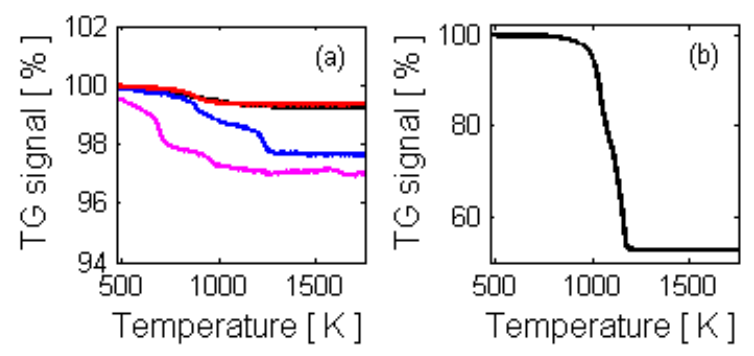

Figure 3: (a) TG signal of (red) olivine, (black) diabase, (blue) anorthosite and (magenta) LD slag (b) TG signal of dolomite as a function of temperature.

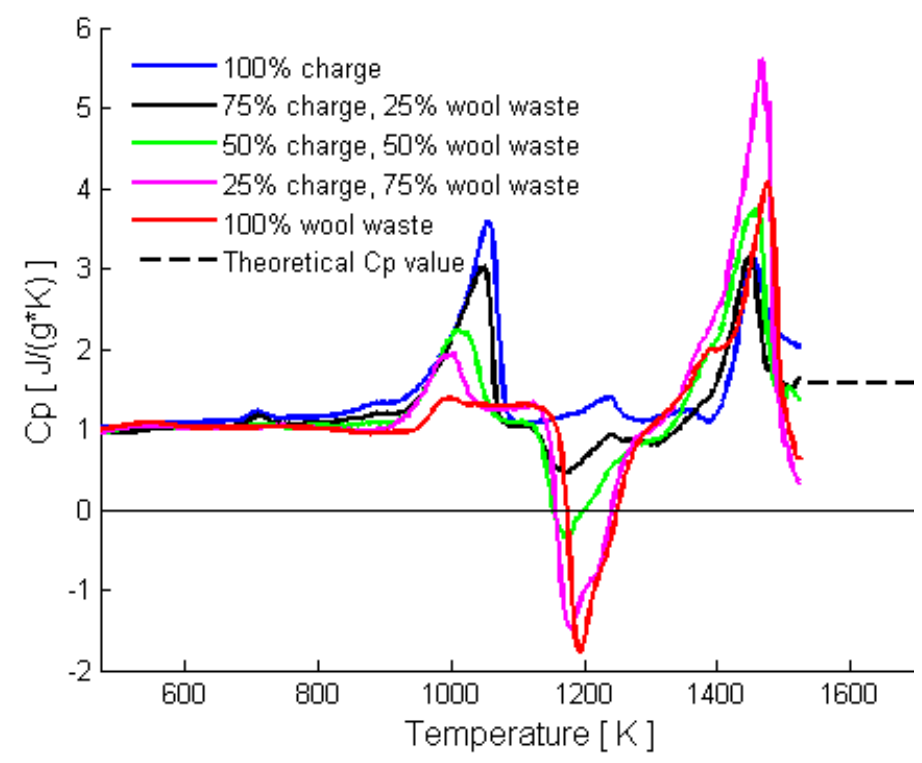

Figure 4: Apparent heat capacities as a function of temperature obtained from DSC measurements of five samples comprising $100 \%, 75 \%, 50 \%, 25 \%$ and $0 \%$ charge and $0 \%, 25 \%, 50 \%, 75 \%$ and $100 \%$ wool waste, respectively. The DSC measurements were conducted at heating rates of $20 \mathrm{~K} / \mathrm{min}$ in Pt crucibles in an $\mathrm{Ar}$ atmosphere. The observed peaks are identified for pure charge and pure wool waste on Figure 2 and explained in the caption text of Figure 2. The dashed line indicates a theoretical value for the melt $C_{p}$ based on the overall melt chemistry, as seen in Table 1, and the method developed by Lange and Navrotsky [23], in which liquid heat capacity of a mixture is calculated as a linear combination of partial molar heat capacities of the oxide components.

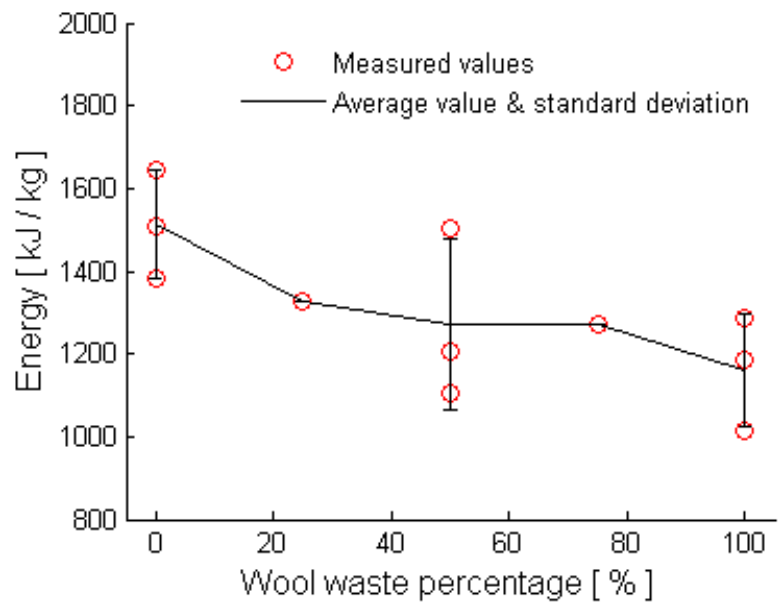

Figure 5: The energy required to heat and melt the total stone wool charge from $473 \mathrm{~K}$ to $1523 \mathrm{~K}$ as a function of the wool waste content. For the samples containing $0 \%, 50 \%$ and $100 \%$ wool waste, a total of three measurements were conducted on similar samples. The red circles represent values obtained from individual measurements and the black curve represents the average values while the vertical line represents the standard deviations.

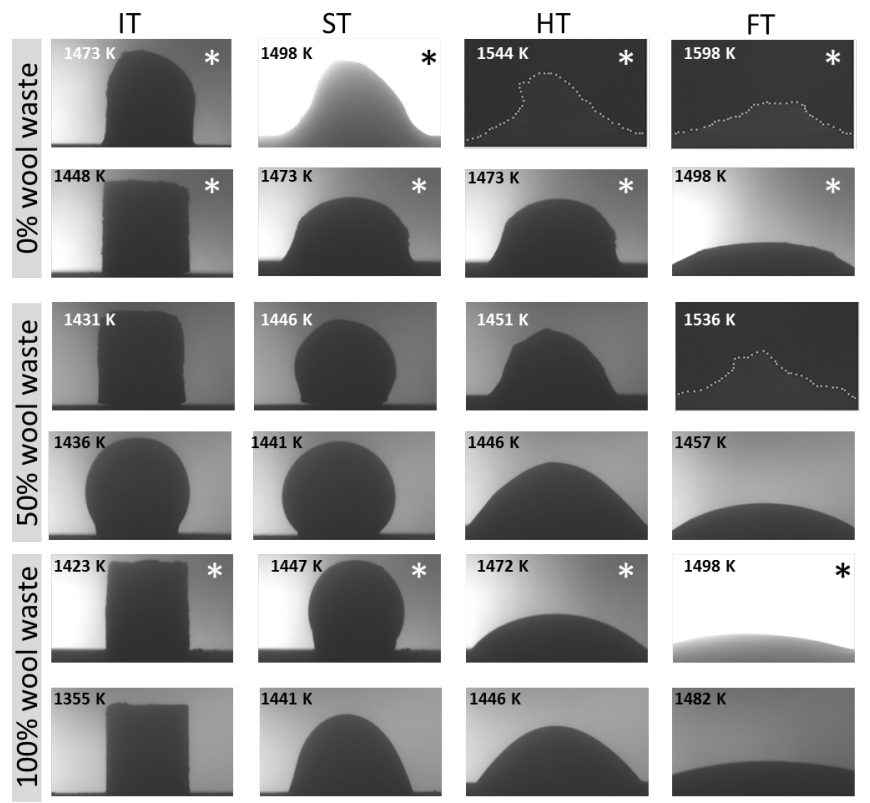

Figure 6: Images obtained from HSM measurements on three samples comprising $100 \%, 50 \%$ and $0 \%$ charge and $0 \%, 50 \%$ and $100 \%$ wool waste, respectively. The samples are heated at $5 \mathrm{~K} / \mathrm{min}$. For each sample two measurements are shown here, one (upper) with original grain size distribution, and one (lower) with crushed samples. The method presented by Stabile et al [22] is used to calculate the temperatures corresponding to characteristic shapes: Initial deformation Temperature (IT), Spherical Temperature, Hemispherical Temperature (HT) and Flow Temperature (FT). For the samples marked with (*) images are obtained every $25 \mathrm{~K}$, for the rest images are obtained every $5 \mathrm{~K}$. 

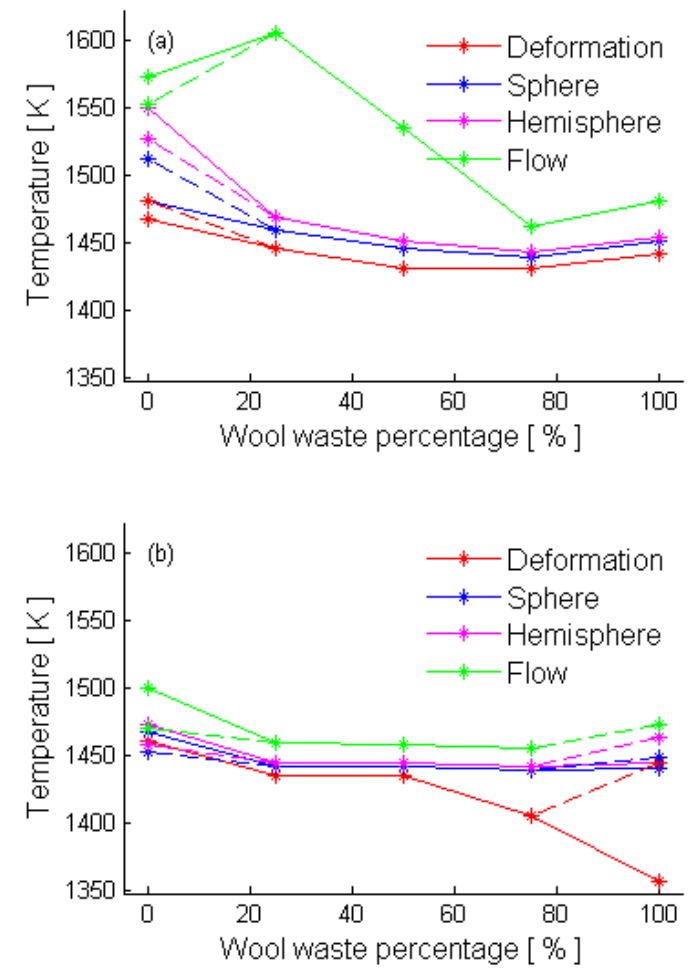

Figure 7: Hot Stage Microscopy of five samples comprising 100\%, 75\%, 50\%, $25 \%$ and $0 \%$ charge and $0 \%, 25 \%, 50 \%, 75 \%$ and $100 \%$ wool waste is used to study the melting behaviour of the samples. A) is a measurements of samples of original grain sizes and B) of crushed samples. All measurements are conducted at a heating rate of $5 \mathrm{~K}$. Four characteristic shapes and their corresponding temperatures are found for each sample. The dashed lines represent results from repetition measurements conducted on the three samples comprising: pure charge (original size), pure charge (crushed) and pure wool (crushed).

\section{Discussion}

\subsection{Raw materials and Charge}

As seen in Figure 2 only three out of the five raw materials studied by DSC show melting peaks in the studied temperature region: anorthosite, p2, known to have a liquidus temperature of 1725-1775 K [24], diabase, p3, is shown to be completely molten at $1473 \mathrm{~K}$ [25] and LD slag, p6, that is a known fluxing agent in steel production [7] and shown to have complete melt formation at $1575 \mathrm{~K}$ on the DSC heating curves.

The remaining peaks observed on the DSC curves are p1 for anorthosite, p4 for dolomite and p5 for LD slag. One of the mineral components in anorthosite, albite, has a phase transition into a high-temperature form when heated above 973 $\mathrm{K}$ [24], this will result in an endothermic peak such as p1. As is seen on Figure 3(a) the phase transition is associated with a $1 \%$ weight loss. Dolomite releases $\mathrm{CO}_{2}$ in a two-step process upon heating [9] resulting in a double peak such as p4 and the $48 \%$ weight loss seen in Figure 3(b). LD slag is rich in calcium and magnesium which typically makes minerals prone to release $\mathrm{CO}_{2}$. p5is accompanied by a $3 \%$ weight loss, as seen on Figure $3(\mathrm{a})$, and is therefore likely to represent a release of $\mathrm{CO}_{2}$.

When comparing the DSC heating curves of the charge with the weighted sum of the individual raw materials, as seen on Figure 2, it is clear that the thermal behaviour of the charge differs significantly from the simple weighted sum. This means that upon heating the raw materials are affected by the presence of the other raw materials.

The mixed charge shows three endothermic peaks at 875$1075 \mathrm{~K}, \mathbf{p} 7$, a small peak at $1225 \mathrm{~K}$, p8, and another large peak at 1375-1575 K, p9. The first peak, p7, overlaps with the decarbonization of dolomite $\mathbf{p 4}$. The pure Dolomite curve on Figure 2 shows a double peak corresponding to a two-step decarbonization whereas in the mixed charge this double peak is reduced to a single peak. This shift is caused by the presence of $\mathrm{SiO}_{2}$, accelerating the decomposition of $\mathrm{CaCO}_{3}$ [26] corresponding to the second peak of the $\mathbf{p} 4$ double peak [9]. The second peak of the mixed charge, $\mathbf{p 8}$ overlaps with the phase transition of albite, p1, and the last peak, p9, with the melting peaks of diabase, p3, and LD slag, p6.

The large endothermic peak on the charge DSC heating curve indicates that the mixed charge melts in the region $1375-1575 \mathrm{~K}$, even though the raw materials anorthosite, olivine sand and dolomite individually does not melt in this region. This indicates that the individual melt generated by diabase at $1325-1575 \mathrm{~K}$ and LD slag at $1425-1575 \mathrm{~K}$ acts as a fluxing agent and the high-temperature resistant raw materials dissolves in the initial melt.

The XRD spectrum obtained for the non-heated pure charge, Figure $8 \mathrm{a}$, shows a great number of peaks reflecting the mineral content of the five raw materials: plagioclase found in anorthosite [8], diopside and quartz found in diabase (according to CIPW calculations), portlandite, belite, srebrodol'skite and $\mathrm{FeO}$ found in LD slag [27], along with the peaks corresponding 
to dolomite and olivine sand. Table 3.3 shows the identified crystal phases for the six spectra in Figure 8.

The XRD spectrum of the charge heated to $1473 \mathrm{~K}$ for 30 minutes (8b) shows fewer peaks than the non-heated charge. These peaks reveal that only some of the raw materials crystal phases remain in the sample at this point. The remaining crystal phases are plagioclase, diopside and olivine corresponding to the raw materials anorthosite, diabase and olivine sand.

The strong dolomite peak at $2 \Theta=31$ has disappeared. This is fully expected from the recrystallization associated with the 2-step $\mathrm{CO}_{2}$ release, seen on the DSC curve in the temperature range $925-1075 \mathrm{~K}$. The peaks corresponding to portlandite, belite and srebrodol'skite all found in LD slag has also disappeared, again supporting the interpretation that the LD slag generates an initial melt in which the remaining raw materials can be dissolved. Diabase is also expected to be a first melt generator, however diopside crystals are still identified in the sample after heat treatment at $1473 \mathrm{~K}$. A previous study has shown diopside to have a melting temperature of $1665 \mathrm{~K}$ at atmospheric pressure [28], explaining why this phase remains present after heat treatment to $1473 \mathrm{~K}$ but disappears after heat treatment to $1623 \mathrm{~K}$ (see Figure 8c). After heat treatment at $1623 \mathrm{~K}$ only a single peak remains in the charge spectrum, Figure $8 \mathrm{c}$, indicating that the material has almost completely transitioned from crystalline form to amorphous form, corresponding to the transition from solid to molten form.

\subsection{Stone wool waste and melting energy}

Wool waste has a fundamentally different thermal response than the charge as seen from the DSC curves on Figure 2 and the apparent heat capacity of wool waste seen on Figure 4. The wool waste heat capacity show a glass transition at 975 K (p10), an exothermic crystallization peak at 1125-1275 K (p11) and a melting peak at 1375-1525 K (12), corresponding to the behaviour known from previous studies [16, 17]. As the measurements are conducted in an inert Ar atmosphere the burning of the organic binder is not seen on the DSC curve.

The crystallization is also reflected in the XRD spectrum on Figure 8e, where a wool waste sample is heated to $1473 \mathrm{~K}$ shows peaks corresponding to the crystal phases Plagioclase and Diopside, whereas the non-heated wool, Figure 8d, does not show any crystal structure. The DSC heating curve, see Figure 2, indicates that the stone wool fibers will melt in the range 1375-1525 $\mathrm{K}$. This corresponds well with the XRD observations that crystal phases remain in the wool waste heated to $1473 \mathrm{~K}$, but does not appear in the stone wool waste heated to $1623 \mathrm{~K}$, as seen on Figure 8f.

The three mixtures of charge and wool waste studied shows characteristics of both the pure charge behaviour and the pure wool waste behaviour. As the wool waste content is increased the heat flow curves gradually resemble that of the pure wool waste more and more, as is seen when comparing the apparent heat capacity curves in Figure 4.
The HSM measurements indicates that the charge of original grain size initiates melting at $1475 \mathrm{~K}$ and is mostly molten at $1575 \mathrm{~K}$, as seen on Figure 7. At $1575 \mathrm{~K}$ some grains remain unmolten, resulting in the corrugated sample outline seen in the upper right corner of Figure 6. The crushed charge sample however appears to be completely molten at $1500 \mathrm{~K}$. The higher liquidus of the non-crushed charge than the crushed charge is probably caused by the fluxing agents experiencing some local transport and mixing limitations in the original grain size sample. The wool waste, of both original grain sizes and crushed, initiates melting around $1450 \mathrm{~K}$ and is completely molten at $1475 \mathrm{~K}$, as seen on Figure 6.

There is a general tendency, that the endothermic melting peaks, as seen between $1325 \mathrm{~K}$ and $1425 \mathrm{~K}$ on Figure 4 start at lower temperatures, than the IT observed in the HSM measurements. This indicates that the samples will already have started the energy consuming phase change before the pellet sample starts to deform. A sample pellet is thus able to contain a certain fraction of molten material before the overall stability of the sample shape is affected substantially.

The melting temperature of these mixed samples depends on the wool waste content to some degree as seen on the upper graph in Figure 7, where the temperatures of the characteristic shapes is lower for higher wool waste content. However the effect of adding wool waste seems to have the largest influence in the step from $0 \%$ to $25 \%$ wool waste. From $25 \%$ wool waste and up, the melting temperature is close to constant.

Generally high flow temperatures are seen for the samples of original grain sizes comprising $0-50 \%$ wool waste. The flow temperature of the samples containing intact raw material grains are highly affected by the position of the largest grains in the sample. As most of the sample does melt during the heating, the larger melt-resistant grains i.e. anorthosite or dolomite grains, stay intact and this results in a corrugated sample contour, as seen for the samples of original grain sizes in Figure 6a. The flow temperature is therefore highly affected by the specific grain sizes and positions inside the sample, explaining the high flow temperatures of the samples of original grain sizes containing large amounts of charge. The flow temperature peak at $25 \%$ is interpreted as a consequence of the composition of that specific sample, and a peak might as well have been observed for the sample of pure charge.

Once the material is crushed the effect of wool waste content on the melting temperature nearly disappears, as seen on Figure $7 \mathrm{~b}$. This points to the mixing effects being dominant in determining melting temperature. The melting temperature of the crushed samples can be seen to be in the region 1430-1475 $\mathrm{K}$ as determined by the span between the sphere temperature and the flow temperature. This interval corresponds well to the interval spanned by the melting peak, p9, of the pure charge seen on Figure 2.

The total energy required for heating the mixed samples 
from $473 \mathrm{~K}$ to $1523 \mathrm{~K}$ does show some large deviations, as seen in Figure 5. The deviations are related to the small sample size of only $22 \mathrm{mg}$, making the measurement highly dependent on the representability of that sample. Also, as the sample begin to melt, the material contracts and begins to move inside the crucible sometimes moving up along the sides of the crucible. The DSC measurements are highly affected by the contact between sample and crucible, and thus as different samples melts and moves differently inside the crucible, the total energy measurement will deviate from sample to sample. In spite of the deviations, a clear linear dependence on the wool waste content is seen: melting pure wool waste requires $23 \%$ less energy than the conventional charge investigated here. The main driver in this difference seems to be the fact that no de-carbonization has to take place when re-melting stone wool waste, thus lowering the overall energy required for the melting process.

\section{Conclusion}

The melting behaviour of a stone wool charge comprising five different raw materials and stone wool waste for recycling is studied with the ultimate goal of understanding the melting process in stone wool production. The conventional charge, comprising five raw materials, and stone wool waste shows fundamentally different thermal responses. The primarily crystalline charge shows a significant release of $\mathrm{CO}_{2}$ and a phase transformation during heating whereas the initially amorphous stone wool waste crystallizes when heated above $850^{\circ} \mathrm{C}$.

The charge melting temperature is lower than the melting temperature of the individual raw materials dolomite, olivine sand and anorthosite. These materials are, when present in the mixed charge, fluxed by the initial melt generated by diabase and LD slag.

As stone wool waste is admixed to the conventional charge, the melting behavior changes linearly with wool waste content. From the measured heat capacities it is seen that pure wool waste requires $23 \%$ less energy for heating and melting than the conventional charge does. The wool waste is therefore a desired material for recycling for energy saving purposes as well as for environmental reasons.

The results presented in this study are valid for a specific chemical composition of stone wool charge and stone wool waste, however the method presented here can be applied to perform studies on any other charge and wool compositions in order to evaluate the potential for energy savings related to adding wool waste to the melting process.

\section{Acknowledgements}

The authors would like to thank the Section of Chemistry at Aalborg University and S. Haastrup for lending us XRD equipment and for guidance and assistance during the measurements.
This work was supported by ROCKWOOL International A/S and Innovation Fund Denmark (grant number: 5189-00019B).

\section{References}

[1] O. Vntsi, T. Krki, Mineral wool waste in Europe: a review of mineral wool waste quantity, quality, and current recycling methods, Journal of Material Cycles and Waste Management 16(1) (2014) 62-72

[2] B. Sirok, B. Blagojevic, P. Bullen, Mineral wool: production and properties, Elsevier, 2008

[3] European Commision, Waste injection into the melting furnace in stone wool production, http://ec.europa.eu/environment/life/project/Projects/index.cfm? fuseaction=home.showFile\&rep=file\&fil=LIFE02_ENV_FIN 000328_LAYMAN.pdf, Acessed: 2017-07-24

[4] K. Heide, R. Franke, H. Schmidt, R. Straussberger, Investigation of the energy expended in heating glass raw materials to the melting temperature, Journal of Thermal Analysis and Calorimetry, 33(3) (1988) 615-618

[5] M. Guldberg, A. de Meringo, O. Kamstrup, H. Furtak, C. Rossiter, The development of glass and stone wool compositions with increased biosolubility, Regulatory toxicology and pharmacology 32(2) (2000) 184-189

[6] M. Guldberg, S. L. Jensen, T. Knudsen, T. Steenberg, O. Kamstrup, High-alumina low-silica HT stone wool fibers: A chemical compositional range with high biosolubility, Regulatory toxicology and pharmacology 35 (2002) 217-226

[7] B. Das, S. Prakash, P. S. R. Reddy, V. N. Misra, An overview of utilization of slag and sludge from steel industries, Resources, conservation and recycling, 50(1) (2007) 40-57

[8] E. I. W. K. Jan, Norweigian anorthosites and their industrial uses, with emphasis on the massifs of the Inner Sogn-Voss area in western Norway, Norges geologiske undersoekelse Bulletin, 436 (2000) 103-112

[9] R. A. W. Haul, H. Heystek, Differential thermal analysis of the dolomite decomposition, Am. Mineral, 37 (1952) 166-179

[10] N. L. Bowen, J. F. Schairer, The system MgO-FeO-SiO2, American Journal of Science, 170 (1935) 151-217

[11] A. Johannsen, A Descriptive Petrography of the Igneous Rocks: Introduction, textures, classifications and glossary, University of Chicago Press, (1931)

[12] K. Hollocker, CIPW norm calculation - Geologynet, https://www.geologynet.com/programs/cipwnormexcel.xls, Accessed on 25.09.2017

[13] R. Leth-Miller, A. D. Jensen, P. Glarborg, L. M. Jensen, P. B. Hansen, S. B. Jrgensen, Experimental investigation and modelling of heat capacity, heat of fusion and melting interval of rocks, Thermochimica acta, 406(1) (2003) 129-142.

[14] W. Eastes, Man-Made Vitreous Fibers: Nomenclature, Chemical and Physical Properties, (1993)

[15] M. M. Smedskjaer, M. Solvang, Y. Yue, Crystallization behaviour and high-temperature stability of stone wool fibres, Journal of the European Ceramic Society, 30(6) (2010) 1287-1295

[16] Y. Yue, M. Korsgaard, L. F. Kirkegaard, G. Heide, Formation of a nanocrystalline layer on the surface of stone wool fibers, Journal of the American Ceramic Society, 92(1) (2009) 62-67

[17] M. Kaasgaard, P. A. L. Jacobsen, Y. Yue, Influence of oxygen partial pressure on crystallization behaviour and high-temperature stability of stone wool fibres, Glass science and technology, 78(2) (2005) 63-68

[18] M. Moesgaard, H. D. Pedersen, Y. Yue, E. R. Nielsen, Crystallization in stone wool fibres, Journal of Non-Crystalline solids, 353(11) (2007) 1101-1108

[19] E. R. Nielsen, M. Augustesen, K. Ståhl, Devitrification and high temperature properties of mineral wool, Materials Science Forum, 558 (2007) 1255-1260

[20] V. Balkevicius, J. Christauskas, A, Gailius, A. Spokauskas, V. Siaurys, Analysis of some properties of model system from low-melting illite clay and fibrous mineral wool waste, Material Science-Poland, 25(1) (2007) 209-217

[21] G. W. H. Höhne, W. F. Hemminger, H.-J. Flammersheim, Differential Scanning Calorimetry, Springer (2003)

[22] F. M. Stabile, M. Piccico, M. F. Serra, M. Rafti, G. Suarez, N. M. Rendtorff, Viscosity and thermal evolution of density and wetting angle of a 
commercial glaze by means of hot stage microscopy, Procedia Materials Science, 9 (2015) 563-570

[23] R. A. Lange, A. Navrotsky, Heat capacities of fe2o3-bearing silicate liquids, Contributions to Mineralogy and Petrology, 110(2) (1992) 311-320

[24] O. F. Tuttle, N. L. Bowen, High-temperature albite and contiguous feldspars, The Journal of Geology 58(5) (1950) 572-583

[25] C. R. Thornber, P. L. Roeder, J. R. Foster, The effect of composition on the ferric-ferrous ratio in basaltic liquids at atmospheric pressure, Geochimica et Cosmochimica Acta, 44(3) (1980) 525-532

[26] K. Sinkó, B. Migaly, M. Gábor, Studies of the silicon dioxide-dolomite system by thermal analysis, Thermochimica Acta, 148 (1989) 473-478

[27] I. Z. Yildirim, M. Prezzi, Chemical, mineralogical, and morphological properties of steel slag, Advances in civil engineering, 2011 (2011)

[28] J. R. Yoder, S. Hatten, Change of melting point of diopside with pressure. The journal of geology, 1952 (60.4) 364-374 

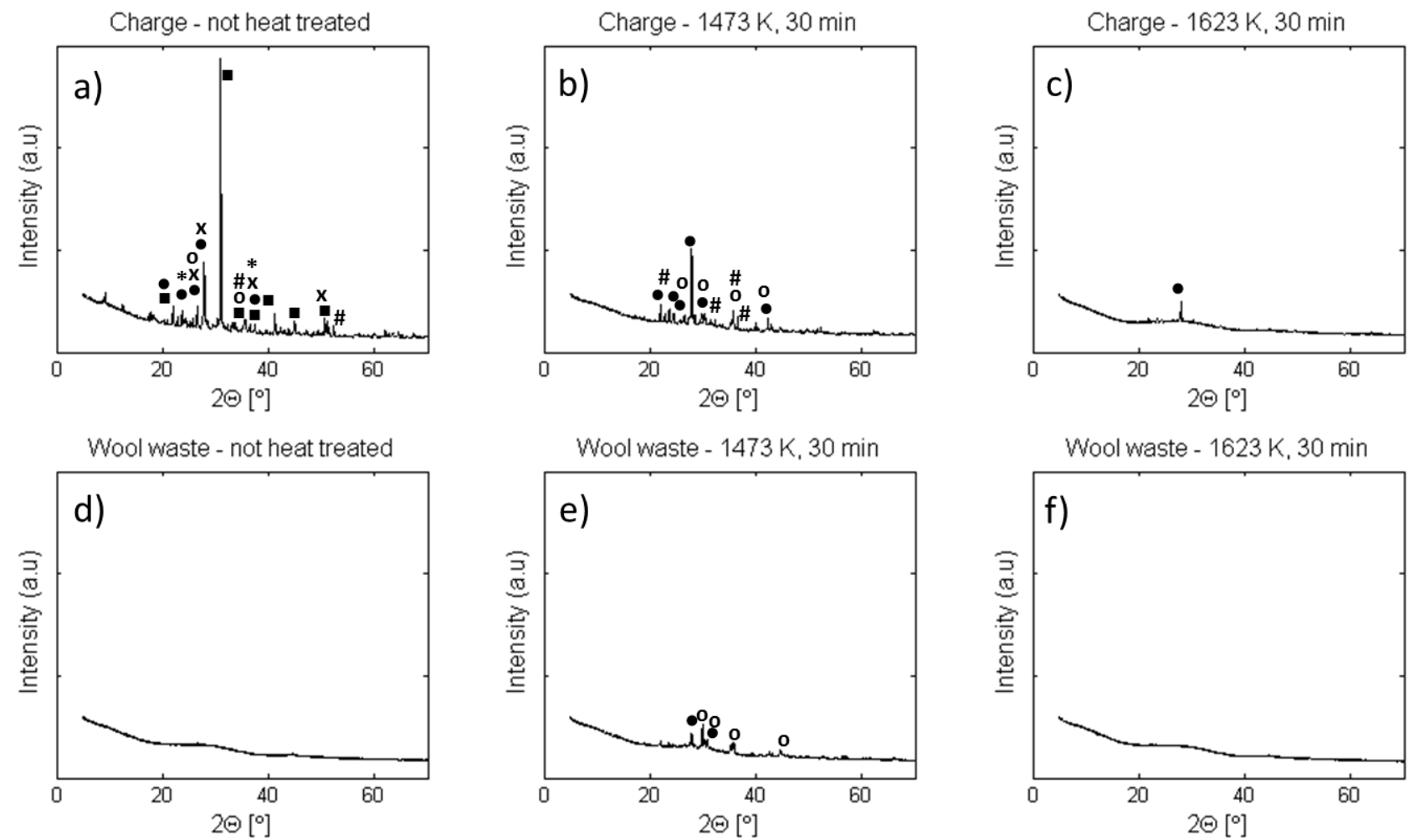

Figure 8: XRD spectra of a) charge, non heated b) charge, $1473 \mathrm{~K}, 30 \mathrm{~min}$ c) charge, $1623 \mathrm{~K}, 30 \mathrm{~min}$ d) wool waste, non heated e) wool waste, $1473 \mathrm{~K}, 30 \mathrm{~min}$ f) wool waste, $1623 \mathrm{~K}, 30 \mathrm{~min}$. The spectra presented here are all a result of a summation over 6 individual measurements with a step size of $0.0130^{\circ}$. The identified crystal phases are plagioclase $(\bullet)$, dolomite $(\boldsymbol{\square})$, diopside $(\circ)$, olivine (\#), srebrodol'skite, $\left(^{*}\right)$ and belite $(\mathrm{x})$. The identified crystal phases are listed in Table 3.3. 